clinical pharmacologists in general seem averse to using substance concentrations; yet it is not unusual for clinicians to receive from their hospital laboratory the results of, say, serum digoxin estimations in $\mathrm{nmol} / \mathrm{l}$. Some agreement here is long overdue, and the present uncertainty will not be dispelled by the thoroughly inadequate advice given in the section on "Pharmaceuticals" in the WHO booklet or by the absence from the table of conversion factors of any drugs other than salicylate, barbiturates, and sulphonamides.

Altogether, we cannot believe that this booklet will do much to commend the SI to those who have not already adopted it or had it thrust upon them, while the statement that "it has been written in a style that makes it suitable for use by all health professionals - specialists, general practitioners, clinical chemists, nurses, and laboratory technicians, to name but a few" is at the very least a little optimistic.

\footnotetext{
${ }^{1}$ Baron, D N, et al, fournal of Clinical Pathology, 1974, 27, 590.

2 World Health Organisation, The SI for the Health Professions. Geneva, WHO, 1977.
}

\section{Diet and asthma}

Some foods may provoke asthma. In young children wheezing may be caused by immediate IgE-mediated allergic reactions after eating eggs, fish, nuts, and chocolate, but it is more commonly due to respiratory infections or inhaled allergens. ${ }^{1-4}$ Positive skin tests are found in about $15^{\circ}$ o of children with asthma, ${ }^{2}$ less often in adults. Allergy to foods is largely an occupational problem for adults with asthma: sensitised workers may develop symptoms while handling grain, flour, coffee, and castor beans. ${ }^{5}$ About $25^{\circ}$ of positive skin tests to foods seem to be clinically relevant, ${ }^{1}$ but food allergy is a dominant factor in less than $1^{\circ}{ }_{0}$ of childhood asthma. ${ }^{2}$ The decline in importance with age of allergy to ingested foods may be due to the development of specific secretory IgA antibodies at the gastrointestinal mucosal surfaces, which prevent the absorption of offending proteins. ${ }^{6}$ Another mechanism is the development of effective blocking antibodies in the blood leading to systemic tolerance. ${ }^{7} 8$

In adults asthma can also be provoked by colouring agents and preservatives in food and drink. Tartrazine, an azo dye widely used for yellow colouring in foods, beverages, and medicines, ${ }^{9}{ }^{10}$ may provoke asthma in sensitive individuals. ${ }^{11} 12$ Reaction to tartrazine seems to be especially common in asthmatics who are also sensitive to acetylsalicylic acid. ${ }^{13} 14$ Sodium benzoate, used as an antibacterial and antifungal agent in food and drink, may also provoke asthma. ${ }^{12} 13$ The pathogenesis of these reactions is uncertain, but they are commoner in non-atopic people, and no recognisable immunological mechanisms have been identified.

In a recent survey of 272 patients with asthma 30 gave a history of wheezing caused by orange drinks but only one wheezed with fresh oranges. ${ }^{15}$ Proprietary orange drinks commonly contain tartrazine with sodium benzoate and sulphur dioxide as preservatives. When 14 of the affected patients were given provocation tests the forced expired volume in one second $\left(\mathrm{FEV}_{1}\right)$ was reduced after drinking solutions of sulphur dioxide in eight cases, after sodium benzoate in four, and after tartrazine in one. Three patients were sensitive to both sulphur dioxide and sodium benzoate. Patients who reacted to sulphur dioxide tended to be young, with extrinsic atopic asthma, while those reacting to sodium benzoate were older and non-atopic. Reactions to sulphur dioxide occurred within 1-2 minutes of ingestion. The effects of sodium benzoate tended to come on after 10 to 20 minutes, as occurs with tartrazine and salicylates. In four patients prior inhalation of sodium cromoglycate protected against reactions to sulphur dioxide, tartrazine, and sodium benzoate.

Exposure to sulphur dioxide may cause an immediate increase in airway resistance in normal persons, ${ }^{16}$ and this substance was thought to be the cause of an increased incidence of episodes of asthma recorded during periods of high atmospheric pollution. ${ }^{17}$ The speed of reaction after ingestion of sulphur dioxide solution is so fast that inhalation rather than gastrointestinal absorption may be the route of sensitisation (though rapid asthmatic reactions have been recorded ${ }^{18}$ with sublingual challenge tests to other substances).

In managing children with asthma the doctor seldom needs to resort to exhaustive skin tests, provocation tests, or trials of exclusion diets-offending foods have usually already been identified and excluded by the patient or parents..$^{15}$ Adults with persistent or troublesome asthma may sometimes benefit from a diet free of additives, and a suitable dietary for use in Britain has recently been published. ${ }^{19}$ The importance of tartrazine as a provoking or exacerbating agent in asthma, especially in adults with aspirin sensitivity and nasal polyposis, requires further investigation. Treatment with sodium cromoglycate is worth a trial in patients with asthma in whom reactions to food additives may be acting as provoking factors.

${ }^{1}$ Hill, L W, New England fournal of Medicine, 1948, 238, 657.

2 Chobot, R, Uvitsky, I H, and Dundy, H, fournal of Allergy, 1951, 22, 106.

${ }^{3}$ Aas, K, International Archives of Allergy, 1966, 29, 346.

${ }^{4}$ Basomba, A, Fournal of Asthma Research, 1967, 5, 129.

${ }^{5}$ Arsdel, P V P, in Bronchial Asthma, eds E B Weiss and M S Segal, p 433. Boston, Little Brown, 1976.

${ }^{6}$ Heremans, J F, and Vaerman, J P, Progress in Immunology, 1971, 1, 875.

'Pomeranz, J R, fournal of Immunology, 1970, 104, 1456.

8 Thomas, H C, and Parrott, D M V, Immunology, 1974, 27, 631

${ }^{9}$ Lockey, S D, Annals of Allergy, 1971, 29, 461.

10 Smith, L J, and Slavin, R G, Fournal of Allergy and Clinical Immunology, $1976,58,456$.

${ }^{11}$ Lockey, S D, Annals of Allergy, 1959, 17, 719

12 Chaffee, F H, and Settipane, G A, Fournal of Allergy, 1967, 40, 65.

${ }^{13}$ Juhlin, L, Michaëlsson, G, and Zetterström, O, fournal of Allergy and Clinical Immunology, 1972, 50, 92.

${ }^{14}$ Stenius, B S M, and Lemola, M, Clinical Allergy, 1976, 6, 119.

15 Freedman, B J, Clinical Allergy, 1977, 7, 407.

${ }_{16}$ Nadel, J S, et al, fournal of Applied Physiology, 1965, 20, 164.

17 Zeidberg, L D, Prindle, R A, and Landau, E, American Review of Respiratory Disease, 1961, 84, 480.

${ }^{18}$ Miller, J B, Food Allergy: Provocative Testing and Injection Therapy. Springfield, Charles Thomas, 1972.

19 Freedman, B J, Clinical Allergy, 1977, 7, 417.

\section{Antibiotic-associated colitis: a progress report}

Both doctors and patients often accept diarrhoea as a natural accompaniment of antibiotic treatment-a price that has to be paid for the benefits of science. The danger of this complacency is that diarrhoea may herald the onset of more serious disturbance. Staphylococcal overgrowth may be associated with a fulminant enterocolitis, ${ }^{12}$ a condition (fortunately rarely seen nowadays) which often had maximum impact on the lower small intestine. At sigmoidoscopy or necropsy some of these patients showed pseudomembrane covering the mucosa of the bowel, but staphylococcal enterocolitis and pseudomembranous colitis are now thought to be separate entities, and the resistant staphylococcus seems to play no part in causing pseudomembranous colitis. ${ }^{3}$ Nevertheless, this latter 